\title{
Diagnosis by endoscopic ultrasound of a large aberrant pancreas mimicking malignant gastrointestinal stromal tumor of the stomach
}

A 78-year-old woman was referred to our hospital complaining of dysphagia and weight loss. Gastroscopy showed a large submucosal lesion at the lesser curvature of the stomach ( $\bullet$ Fig. 1). Computed tomography (CT) scan revealed a large tumor at the lesser curvature of the stomach ( Fig. 2), which was diagnosed as a gastrointestinal stromal tumor (GIST) of the stomach. However, endoscopic ultrasonography (EUS) showed a heterogeneous lesion with a small anechoic area ( $\bullet$ Fig. 3), which was suspected to be aberrant pancreas or malignancy. The patient was successfully treated surgically by wide excision of the lesion ( $\bullet$ Fig. 4). Pathological examinations confirmed a diagnosis of aberrant pancreas ( $\bullet$ Fig. 5). Aberrant pancreas is defined as pancreatic tissue lying outside of its normal location and lacking anatomic or vascular connections with the pancreas. It does not usually cause symptoms and is found incidentally in the stomach, duodenum, small intestine, Meckel's diverticulum [1], or biliary tract at upper endoscopy, upper gastrointestinal contrast radiography, laparotomy, or autopsy [2,3]. Therefore, aberrant pancreas is not a great problem in the clinical setting. Complications of aberrant pancreas usually include inflammation with formation of an inflammatory mass, ulceration, bleeding, and obstruction, with clinical manifestations of acute and chronic pancreatitis [4].

Aberrant pancreas mimicking a malignant GIST of the stomach is extremely rare, and it is difficult to obtain adequate tissue from the lesion. The present case suggests that the finding of a large submucosal tumor of the stomach with central umbilication and heterogeneous lesions with small anechoic areas, as defined by endoscopy and EUS, could indicate suspected aberrant pancreas. If the diagnosis is uncertain, the use of aggressive techniques instead of EUS alone, including EUS-guided biopsy possibly with surgical resection, should be advocated.

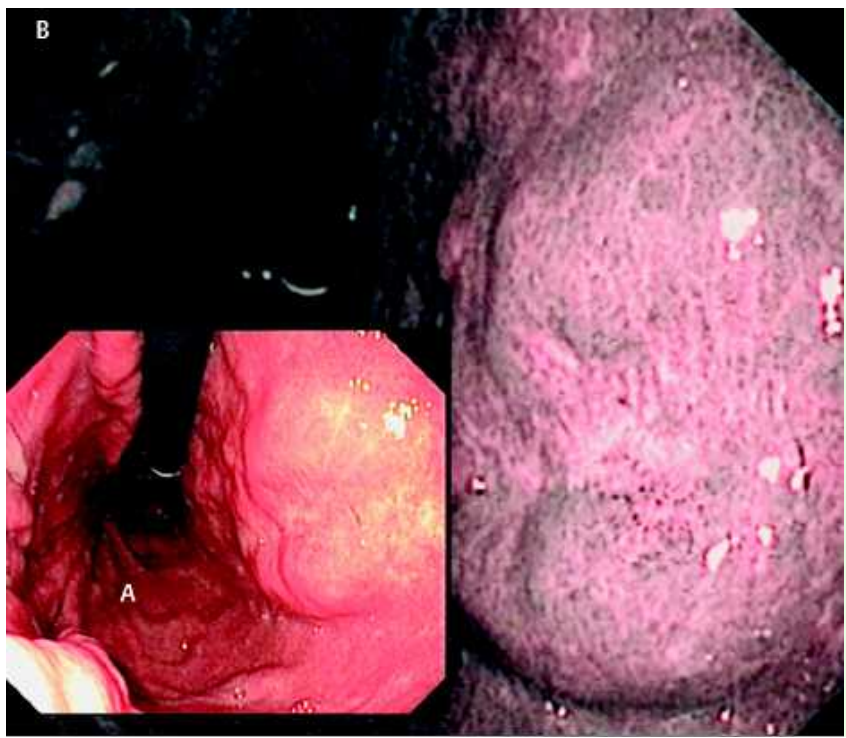

Fig. 1 Appearance of the submucosal lesion with central umbilication at the body of the stomach. a Endoscopic view, with (b) narrowband imaging.

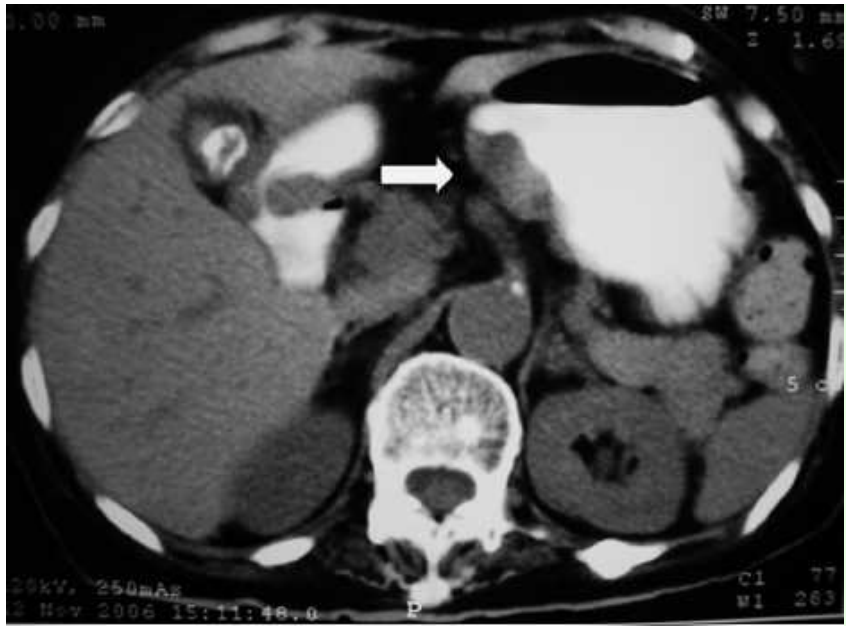

Fig. 2 Computed tomography scan revealed a large submucosal lesion at the lesser curvature of the stomach (white arrow).

Endoscopy_UCTN_Code_CCL_1AB_2AC_3AB Endoscopy_UCTN_Code_CCL_1AF_2AD

\section{T. Akaraviputh ${ }^{1}$, A. Manuyakorn ${ }^{2}$, V. Lohsiriwat ${ }^{1}$}

Siriraj GI Endoscopy Center, Department of Surgery, Siriraj Hospital, Mahidol University, Bangkok, Thailand Department of Pathology, Siriraj Hospital, Mahidol University, Bangkok, Thailand
References

1 Curd HH. A histologic study of Meckel's diverticulum. Arch Surg 1936; 32: 506-523

2 De astro Barbosa JJ, Dockerty MB, Waugh JM. Pancreatic heterotopia: review of the literature and report of 41 authenticated surgical cases, of which 25 were clinically significant. Surg Gynecol Obstet 1946; 82: 527 542

3 Dolan RV, ReMine WH, Dockerty MB. The fate of heterotopic pancreatic tissue: a study of 212 cases. Arch Surg 1974; 109: 762 - 765

4 Marshall SF, Curtiss FM. Aberrant pancreas in stomach wall. Surg Clin North Am 1952; 32: 867-875 


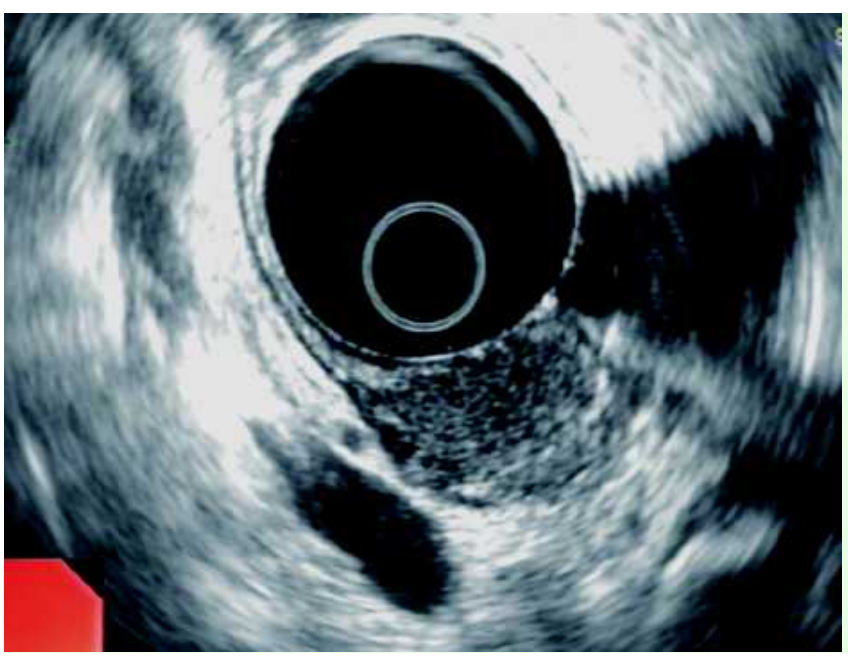

Fig. 3 A large submucosal mass was seen at the body of the stomach by radial endoscopic ultrasound (Olympus, Tokyo, Japan). The lesion was heterogeneous with a small anechoic area.

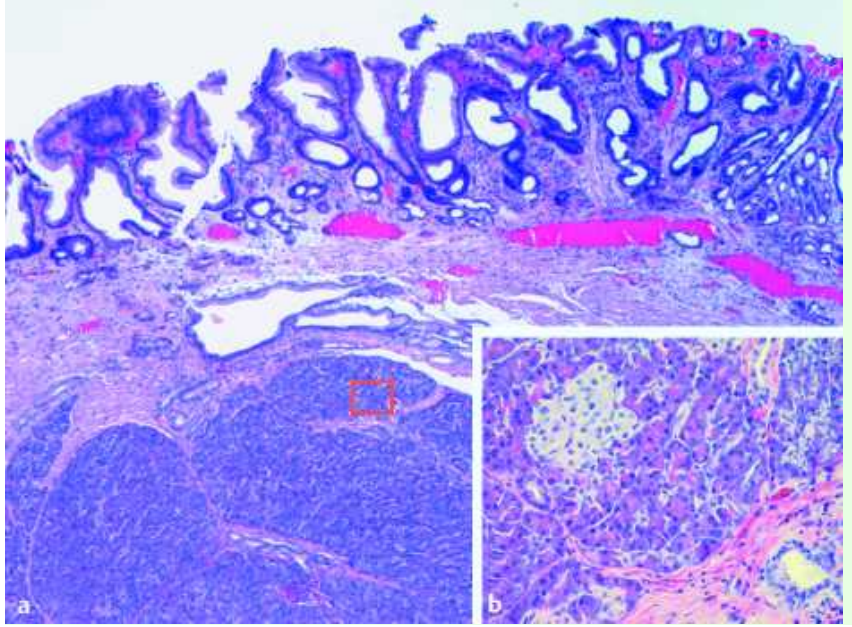

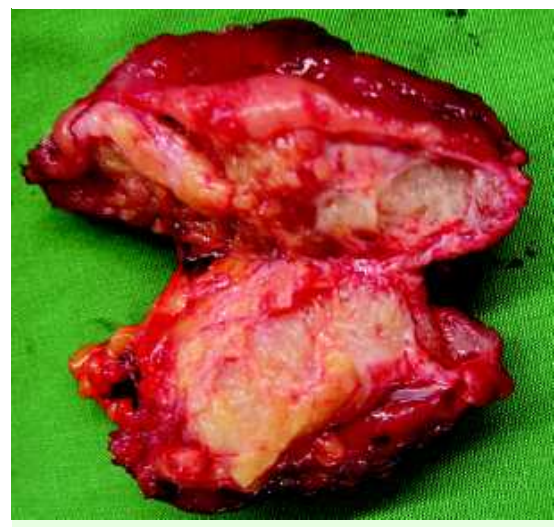

Fig. 4 Gross examination shows a yellow rubbery intramural mass with ill-defined borders, measuring $3.5 \times 2.5 \times 1.5 \mathrm{~cm}$.

Bibliography

DOI $10.1055 / \mathrm{s}-0028-1119457$

Endoscopy 2009; 41: E63-E64

(c) Georg Thieme Verlag KG Stuttgart · New York . ISSN 0013-726X

\section{Corresponding author}

\section{T. Akaraviputh, MD}

Department of Surgery

Faculty of Medicine

Siriraj Hospital

Mahidol University

Bangkok, 10700

Thailand

Fax: $+66-2-4121370$

sitak@mahidol.ac.th 